\title{
ENHANCING DIMENSIONAL STABILITY OF ORIENTED STRAND COMPOSITES WITHIN BIOREFINERY
}

\author{
Zeki Candan ${ }^{1, \star}$, Stephen M. Shaler ${ }^{2}$, Juan Jacobo Paredes Heller ${ }^{3}$, Russell Edgar ${ }^{2}$
}

\begin{abstract}
The objective of this study was to investigate the effects of hot water extraction process on the dimensional stability of oriented strand composites. Aspen wood strands were extracted using various severity factor levels. Phenol formaldehyde and polymethylene diphenyl diisocyanate resins were used for production of the oriented strandboard panels. Six panel groups were produced from the extracted or unextracted aspen wood strands. The dimensional stability of the material was evaluated by measures of equilibrium moisture content and thickness swell and water absorption after soaking in water for 2 hours and 24 hours. Results obtained in this study showed that thickness swell and water absorption values significantly decreased with the hot water extraction process, with the thickness swell of phenol formaldehyde bonded panels decreasing $70 \%$ after 2 hours soaking. The panels with polymethylene diphenyl diisocyanate resin exhibited lower thickness swell and water absorption relative to the panels prepared with phenol formaldehyde resin. Equilibrium moisture content values of the panels bonded with both phenol formaldehyde and polymethylene diphenyl diisocyanate resin decreased with the extraction process. The findings of this work indicate that hot water extraction process could be effectively used to produce oriented strand composites having an enhanced dimensional stability property.
\end{abstract}

Keywords: Hot water extraction, phenol formaldehyde adhesive, polymethylene diphenyl diisocyanate adhesive, water absorption, wood composites.

\section{INTRODUCTION}

Widespread raw material sources for energy, food, and human civilization depended almost entirely on renewable materials from forestry and agriculture before 1900s. The industrial revolution was brought to maturity by the development of combustion engines and subsequent development of fossil energy and chemical industry. However, energy and chemicals derived from non-renewable sources have long-term implications. Changing the present industry and human civilization to a sustainable mode is an important necessity (Liu et al. 2010).

The use of wood material for bio-fuel production is receiving considerable interest, primarily through conversion of the cellulosic component. However, the conversion of wood to bio-fuel is not yet wide-spread due to technical and economic barriers. A variety of processes are used in biorefineries to convert biological materials into products including; thermochemical (pyrolysis of biomass for fuel), chemical (production of poly lactic acid), and biocatalytic methods including enzymatic biocatalysis (cellulase treatment of cellulosic biomass and whole-cell biocatalysis including fermentation) (Lasure and Zhang 2004, Tan and Xu 2010, Agnihotri et al. 2015, Dziurka et al. 2015).

\footnotetext{
${ }^{1}$ Department of Forest Products Engineering, Faculty of Forestry, Istanbul University, Sariyer, Istanbul, Turkey.

${ }^{2}$ School of Forest Resources, Advanced Structures and Composites Center, University of Maine, Orono, ME, USA.

${ }^{3}$ Universidad Nacional Autónoma de Honduras Tecnológica de Aguán (UNAH-TEC), Honduras.

•Corresponding author: zekic@istanbul.edu.tr

Received: 14.09.2015 Accepted: 21.05.2017
} 
World ethanol production in 2004 was 10770 million gallons (40765 billion liters) and exceeded of 11500 million gallons (4353 billion liters) in 2005. Ethanol in excess of 3 million gallons for per year (11,5 million liters) capacity was produced more than 33 countries. Production in the United States is expected to increase from 4,25 billion gallons (16 billion liters) in 2005 to 7,5 billion gallons per year $(28,39$ liters $)$ in 2013. The renewable fuel standard (RFS, U.S. Energy Bill) will guarantee a market for the increasing ethanol volume directed to the fuel markets by virtue of mandating 10 percent ethanol in U.S. gasoline by 2013 (Paszner 2006).

The primary chemical components of wood are cellulose, hemicelluloses, and lignin. Hemicelluloses are the most easily removed of the main biopolymers. They are also amorphous bio-polymers, heteropolysaccharides, relatively easily hydrolyzed by acids into their monomeric components (Shimizu 1990, Pelaez-Samaniego et al. 2013). Tunc and van Heiningen (2008) reported that hemicelluloses derived from biomass are currently underutilized. Hemicelluloses have been described as a feedstock for higher value added materials production such as ethanol, polymers, and chemicals (van Heiningen 2006).

Wood-based composite panels such as plywood, LVL (laminated veneer lumber), and OSB (oriented strand board) have been replacing solid wood materials in many structural applications (Unsal et al. 2010). OSB production capacity in North America exceeded 25 million cubic meters and exceeded 4 million cubic meters in Europe by 2007. More recently OSB production has spread to Latin America where production capacity reached almost a half million cubic meters by 2007 . There are plans to establish new OSB mills in Australia, China, and Latvia (BIS Shrapnel 2008). Additional OSB mills are being planned or under construction, bringing the total number of facilities in the world to over 80 in 2009 in the world (TECO 2009). Wood-based panel manufacturers could benefit from the extraction of hemicellulose from their raw materials (Mosier et al. 2005). OSB manufacturers also hold potential advantages for bio-ethanol production because they already use wood strands.

Dimensional stability performance is of great importance for wood and wood composites. Dimensional changes become important when large panel sizes are used or when the expansion is totally or partially restrained (Wu and Suchsland 1996). Effects of various production parameters on dimensional stability of OSB were previously studied by Brochmann et al. (2004), Zisi et al. (2005), Del Menezzi and Tomaselli (2006), Wan and Kim (2006), Ayrilmis et al. (2007), Han et al. (2007), Okino et al. (2007), Sumardi et al. (2007), Del Menezzi et al. (2009), Unsal et al. (2009), Candan et al. (2011), Mendes et al. (2013a), Mendes et al. (2013b). Paredes et al. (2008) studied physical and mechanical properties of pMDI bonded OSB panels made from hot water extracted red maple (Acer rubrum) wood strands. Sattler et al. (2008) also investigated influences of hot water extraction on physical and chemical properties of OSB wood strands. Sekino et al. (2005) evaluated the effect of steam pretreatment procedure on dimensional stability properties of particleboard panels. Pelaez-Samaniego et al. (2014) investigated effects of a hot-water extraction method on properties of particleboard panels.

There is limited data available in the literature investigating the effects of the hemicellulose extraction process and resin type on the dimensional stability of oriented strand composites. The goal of this study was to evaluate the effect of hot water extraction on the dimensional stability performance of aspen (Populus) oriented strand composites bonded with phenol formaldehyde (PF) or polymethylene diphenyl diisocyanate (pMDI) resin. 


\section{EXPERIMENTAL}

\section{Materials}

Aspen (Populus tremuloides) wood strands were used for production of oriented strandboard (OSB) panels. Fines content of wood strands was $5 \%$. Moisture content (MC) of the strands was approximately $5 \%$ before blending. Phenol formaldehyde (PF) and polymethylene diphenyl diisocyanate (pMDI) resins were used. Surface and core resins were used for the phenol formaldehyde panels. The surface strand PF resin had a $54,5 \%$ solids content while $45 \%$ solids PF resin was used for the core strands. pMDI resin with $100 \%$ solid content was used for surface strands and core strands. $1 \%$ wax with $58 \%$ solid content was used for PF and pMDI resins.

\section{Hot water extraction process}

A pilot plant type rotating extractor with computer control was used to perform the hot water extraction (HWE) procedure. First, aspen wood strands were placed into the vessels and then filled with fresh water. The vessels were then closed, and the digester was heated from room temperature to $160^{\circ} \mathrm{C}$ with a preheating time of $50 \mathrm{~min}$. After the preheating period constant temperature was applied with exposure times of 45 or $90 \mathrm{~min}$. These two HWE parameters were equated to a severity factor (SF) through the use of Eq. 1 (Overend and Chornet 1987, Mosier et al. 2002). After the HWE process, the covers were removed from the vessels and extracted aspen wood strands were taken out.

$$
S F=\log \left(\int_{0}^{t} \operatorname{Exp}\left[\frac{(T r-T b)}{14,75}\right] d t\right)
$$

where, $\mathrm{t}$ is the residence time $(\mathrm{min}), \operatorname{Tr}$ is the reaction temperature $\left({ }^{\circ} \mathrm{C}\right)$, and $\mathrm{Tb}$ is the base temperature at $100{ }^{\circ} \mathrm{C}$. The temperature difference is $14,75\left({ }^{\circ} \mathrm{C}\right)$ derived from $\left\{\frac{(\operatorname{Tr} \times \operatorname{Tb} \times R}{E a}\right\}$ assuming that the overall process is hydrolytic and the overall conversion is pseudo first order (Overend and Chornet 1987, Mosier et al. 2002). Bonds on SF equation are from 0 (unextracted wood) to 2. SF values were calculated as 3,56 and 3,84 for 45 and 90 min extraction times, respectively, using Eq. 1 .

Weight loss (WL) values of the extracted aspen wood strands were calculated for each extraction level by freeze drying the extracted liquid (Table 1). A $25 \mathrm{~mL}$ sample of the extracted liquid from each extraction level was placed in a freeze dryer (LABCONCO model LYPH-lock 6) at a temperature of $-42^{\circ} \mathrm{C}$ and vacuum of 1,3-1,5 Pa for approximately 48 hours. Each sample was weighed before freeze drying and after freeze drying. Following equation 2 was used to calculate WL values.

$$
\% W L\left\{\frac{E\left(\frac{S}{L}\right)}{W}\right\} 100
$$

where, $\mathrm{S}$ is the weight in grams of solid fraction from the freeze drier, $\mathrm{L}$ is the weight in grams of sample of extract put into the freeze drier, $\mathrm{E}$ is the weight in grams of liquid extract resulting from each extraction, and $\mathrm{W}$ is the weight in grams of the oven dried wood. 
Table 1. Weight loss values of the strands after hot-water extraction process.

\begin{tabular}{|c|c|c|}
\hline Hot Water Extraction & Severity Factor (SF) & Weight Loss (\%) \\
\hline Control & - & - \\
\hline LSF & 3,56 & 13,6 \\
\hline HSF & 3,84 & 17,3 \\
\hline
\end{tabular}

\section{Panel manufacturing}

Strands were blended with PF or pMDI resins and wax in a rotary drum blender with a Coil spinning disc atomizing system. Speed of the drum blender was $20 \mathrm{rpm}$ while speed of the atomizer was $12000 \mathrm{rpm}$. The resins and wax used in this study were supplied from Georgia Pacific Inc. Six percent pMDI or PF resins and one percent wax were loaded to aspen wood strands. Solid contents of resin and wax were calculated based on oven dried wood weight. Resin addition rate to the blender was $125 \mathrm{~g} / \mathrm{min}$. Blended strands were then formed by hand in a forming box of size 34 inches by 34 inches. For pMDI resin, a release agent was sprayed onto steel plates to prevent bonding between final panel and the plates. After the forming process, three layer mats were pressed in a computer-controlled laboratory type hot press. Press temperature was $400^{\circ} \mathrm{F}$ for both PF and pMDI bonded (Oriented Strand Composites) OSC panels. Total pressing time was four minutes. Target panel density was $40 \mathrm{lb} / \mathrm{ft}^{3}$ (640 $\left.\mathrm{kg} / \mathrm{m}^{3}\right)$. Dimensions of the OSC panels were 34 inches by 34 inches by $7 / 16(0,438)$ inches $(863,6 \mathrm{~mm}$ x $863,6 \mathrm{~mm}$ x 11,12 mm). Pressed panels were then trimmed to their final dimensions. Experimental design of the panels is shown in Table 2. A total of nine OSC panels, two PF bonded panels for each severity factor levels and one pMDI bonded panel for each severity factor, were produced.

Table 2. Experimental design of the panels.

\begin{tabular}{|c|c|c|}
\hline Panel No & HWE & Resin Type \\
\hline C-PF & Control & PF \\
\hline L-PF & LSF & PF \\
\hline H-PF & HSF & PF \\
\hline C-PM & Control & pMDI \\
\hline L-PM & LSF & pMDI \\
\hline H-PM & HSF & pMDI \\
\hline
\end{tabular}

\section{Testing procedure}

\section{Thickness swell and water absorption}

Each panel was cut into four samples $(152 \mathrm{~mm} \times 152 \mathrm{~mm})$ which were then conditioned to $20^{\circ} \mathrm{C} / 65 \% \mathrm{RH}$ until they reached an equilibrium condition. Thickness swell (TS) and water absorption (WA) tests were conducted according to ASTM D1037-06a (ASTM 2006). After conditioning, all samples were weighed and thickness was measured. Specimens were immersed (horizontal) in water $\left(20^{\circ} \pm 1^{\circ} \mathrm{C}\right)$ with edge thickness swell and 1-inch inside TS and WA performance determined after 2 hours or 24 hours. 


\section{Equilibrium moisture content}

Equilibrium moisture content (EMC) test were conducted according to ASTM D1037-06a (ASTM 2006). Four samples with dimensions of 152 by $152 \mathrm{~mm}$ for each group were prepared to determine EMC values. After the 24 hour water soaking period the WATS samples were dried in an oven at $103^{\circ} \mathrm{C}$ until constant weights were reached and then weighed. In addition, moisture content (MC) values of the specimens after 2 hour ( $2 \mathrm{~h}$ ) or 24 hour $(24 \mathrm{~h})$ water soaking period were calculated based on the oven-dry weight of each specimen.

\section{Statistical analysis}

To evaluate dimensional stability performance of the OSC panels, all multiple comparisons were first tested using an analysis of variance (one-way ANOVA) at $p<0,05$. Significant differences between the mean values of treated and untreated groups were determined using Duncan's multiple range test.

\section{RESULTS AND DISCUSSION}

\section{Inch and edge thickness swell}

One inch inside and edge thickness swell (TS) results for the PF or pMDI bonded OSC panels after both $2 \mathrm{~h}$ and $24 \mathrm{~h}$ water soaking time are shown in Table 3 . The results indicate that $1 \mathrm{in}$. TS and edge TS values of both PF and pMDI bonded OSC panels made from HWE aspen wood strands were significantly lower than those of untreated panels for both $2 \mathrm{~h}$ and $24 \mathrm{~h}$ water soaking period.

As shown in Table 3, the highest 1 inch TS results for $2 \mathrm{~h}$ and $24 \mathrm{~h}$ were obtained in the panels made from unextracted strands for PF bonded panels while the lowest values were obtained in the panels made from HWE strands with a high severity factor. One inch TS after $2 \mathrm{~h}$ and $24 \mathrm{~h}$ water immersion of the panels with PF decreased with increasing HWE levels and were improved by $70 \%$ and $57 \%$, respectively. One inch TS values after $2 \mathrm{~h}$ water exposure of the panels with pMDI decreased with increasing HWE levels. However, the difference among the groups was not significant. One inch TS values after $24 \mathrm{~h}$ water exposure of the panels with pMDI also decreased as HWE levels increased and the differences between the three panel groups were statistically significant. 
Table 3. Thickness swell (1-inch and edge) results of PF or pMDI bonded panels.

\begin{tabular}{|c|c|c|c|c|c|}
\hline \multirow{2}{*}{ Panel No } & \multirow{2}{*}{$\begin{array}{c}\text { Panel } \\
\text { Density } \\
\left(\mathrm{kg} / \mathrm{m}^{3}\right)\end{array}$} & \multicolumn{2}{|c|}{1 inch TS (\%) } & \multicolumn{2}{|c|}{ Edge TS (\%) } \\
\hline & & $2 \mathrm{~h}$ & $24 \mathrm{~h}$ & $2 \mathrm{~h}$ & $24 \mathrm{~h}$ \\
\hline & \multicolumn{5}{|c|}{ PF resin bonded panels } \\
\hline C-PF & 679,6 & $\begin{array}{c}6,34(\mathrm{~A}) \\
(24,72)\end{array}$ & $\begin{array}{c}14,69(\mathrm{~A}) \\
(17,80)\end{array}$ & $\begin{array}{c}9,81(\mathrm{~A}) \\
(20,12)\end{array}$ & $\begin{array}{r}20,01(\mathrm{~A}) \\
(16,99)\end{array}$ \\
\hline L-PF & 686,2 & $\begin{array}{l}2,54(\mathrm{~B}) \\
(20,37)\end{array}$ & $\begin{array}{l}6,88(\mathrm{~B}) \\
(13,08)\end{array}$ & $\begin{array}{c}4,05(\mathrm{~B}) \\
(9,19)\end{array}$ & $\begin{array}{c}10,86(\mathrm{~B}) \\
(9,26)\end{array}$ \\
\hline $\mathrm{H}-\mathrm{PF}$ & 700,5 & $\begin{array}{l}1,97(\mathrm{~B}) \\
(18,23)\end{array}$ & $\begin{array}{l}6,28(B) \\
(17,04)\end{array}$ & $\begin{array}{c}3,77 \text { (B) } \\
(15,04)\end{array}$ & $\begin{array}{c}10,57(\mathrm{~B}) \\
(6,87)\end{array}$ \\
\hline \multicolumn{6}{|c|}{ pMDI resin bonded panels } \\
\hline C-PM & 671,7 & $\begin{array}{c}3,28(\mathrm{~A}) \\
(30,25)\end{array}$ & $\begin{array}{c}9,62(\mathrm{~A}) \\
(8,67)\end{array}$ & $\begin{array}{c}7,15(\mathrm{~A}) \\
(2,27)\end{array}$ & $\begin{array}{c}15,68(\mathrm{~A}) \\
(2,10)\end{array}$ \\
\hline L-PM & 666,0 & $\begin{array}{c}2,87(\mathrm{~A}) \\
(21,96)\end{array}$ & $\begin{array}{c}7,43(\mathrm{~B}) \\
(8,82)\end{array}$ & $\begin{array}{l}4,69(\mathrm{~B}) \\
(17,62)\end{array}$ & $\begin{array}{c}10,04(\mathrm{~B}) \\
(9,68)\end{array}$ \\
\hline H-PM & 679,7 & $\begin{array}{c}2,36(\mathrm{~A}) \\
(42,69)\end{array}$ & $\begin{array}{l}5,59(\mathrm{C}) \\
(22,73)\end{array}$ & $\begin{array}{r}3,34(\mathrm{C}) \\
(15,25)\end{array}$ & $\begin{array}{r}8,47(\mathrm{C}) \\
(15,82)\end{array}$ \\
\hline
\end{tabular}

Groups with same letters in column indicate that there is no statistical difference $(p<0,05)$ between the samples according to the Duncan's multiple range test. Coefficient of variation values (\%) are in parentheses.

Table 3 clearly shows the edge TS values after $2 \mathrm{~h}$ and $24 \mathrm{~h}$ water immersion of the panels made from extracted strands using PF resin were significantly less than those of the panels made from unextracted strands. Edge TS values after $2 \mathrm{~h}$ and $24 \mathrm{~h}$ water immersion of the panels using PF resin decreased with increasing SF level and were improved by $62 \%$ and $47 \%$, respectively. Duncan's range test results indicate that the edge TS values after $2 \mathrm{~h}$ and $24 \mathrm{~h}$ water exposure of the panels made from HWE strands were significantly lower than those of the panels made from untreated strands for pMDI resin. The panels from treated strands using the high severity factor (HSF) had the lowest edge TS value while the panels from control strands had the highest edge TS values. Table 3 indicates that the edge TS values after both $2 \mathrm{~h}$ and $24 \mathrm{~h}$ water immersion of the pMDI bonded panels made from unextracted, extracted with low severity factor (LSF), and extracted with HSF were statistically significant.

Lenic (1973) and Myers (1982) stated that extraction of hemicellulose from wood using high pressure steam caused a reduction in thickness swell of wood material. Similar findings were obtained by Paredes et al. (2008) who evaluated the effects of HWE on the TS behavior of OSB. Paredes et al. (2008) found the panels made from extracted strands had lower TS values after $24 \mathrm{~h}$ water immersion period than that of the panels made from unextracted strands. 


\section{Water absorption}

Water absorption (WA) values after both $2 \mathrm{~h}$ and $24 \mathrm{~h}$ water soaking time of the OSC panels bonded with PF or pMDI resin are shown in Table 4. The results determined in this study reveal that the panels made from extracted wood strands for PF or pMDI resin had significantly lower WA values after $2 \mathrm{~h}$ and $24 \mathrm{~h}$ water soaking time than the panels made from unextracted wood strands. Different results were reported in one of the previous studies performed by Paredes et al. (2008) who stated that water absorption values after both $2 \mathrm{~h}$ and $24 \mathrm{~h}$ water soaking period of the panels made from extracted strands were higher than those of the panels from unextracted strands.

As shown in Table 4 , the lowest WA values after $2 \mathrm{~h}$ and $24 \mathrm{~h}$ water immersion periods were obtained in the panels made from extracted wood strands with HSF while the highest values were determined in the panels made from unextracted wood strands for PF resin. Similarly, the lowest WA values after $2 \mathrm{~h}$ and $24 \mathrm{~h}$ water soaking time were obtained in the panels made from extracted panels with HSF for pMDI resin. The results obviously indicate that the HWE process of the aspen wood strands significantly improved WA resistant after both $2 \mathrm{~h}$ and $24 \mathrm{~h}$ water immersion periods of the PF or pMDI bonded OSC panels.

Table 4. Water absorption and MC results of PF or pMDI bonded panels.

\begin{tabular}{|c|c|c|c|c|c|}
\hline \multirow{2}{*}{ Panel No } & \multicolumn{2}{|c|}{ WA $(\%)$} & \multicolumn{3}{|c|}{$\mathrm{MC}(\%)$} \\
\hline & $2 \mathrm{~h}$ & $24 \mathrm{~h}$ & & $2 \mathrm{~h}$ & $24 \mathrm{~h}$ \\
\hline & \multicolumn{5}{|c|}{ PF resin bonded panels } \\
\hline $\mathrm{C}-\mathrm{PF}$ & $\begin{array}{c}9,87(\mathrm{~A}) \\
(16,72)\end{array}$ & $\begin{array}{c}26,24(\mathrm{~A}) \\
(9,99)\end{array}$ & $\begin{array}{c}8,00(\mathrm{~A}) \\
(5,04)\end{array}$ & $\begin{array}{c}19,08(\mathrm{~A}) \\
(11,50)\end{array}$ & $\begin{array}{c}36,91 \\
(\mathrm{~A}) \\
(9,17)\end{array}$ \\
\hline L-PF & $\begin{array}{c}8,39(\mathrm{~A}) \\
(15,69)\end{array}$ & $\begin{array}{c}25,16(\mathrm{~A}) \\
(14,72)\end{array}$ & $\begin{array}{c}6,35(\mathrm{~B}) \\
(3,89)\end{array}$ & $\begin{array}{c}15,27 \text { (B) } \\
(9,82)\end{array}$ & $\begin{array}{c}33,11 \\
(\mathrm{~A}) \\
(12,51)\end{array}$ \\
\hline $\mathrm{H}-\mathrm{PF}$ & $\begin{array}{l}6,10(\mathrm{~B}) \\
(17,34)\end{array}$ & $\begin{array}{c}18,34(\mathrm{~B}) \\
(15,69)\end{array}$ & $\begin{array}{c}6,34(\mathrm{~B}) \\
(5,49)\end{array}$ & $\begin{array}{c}12,76(\mathrm{C}) \\
(9,16)\end{array}$ & $\begin{array}{c}25,77 \\
(\mathrm{~B}) \\
(13,08)\end{array}$ \\
\hline & \multicolumn{5}{|c|}{ pMDI resin bonded panels } \\
\hline C-PM & $\begin{array}{c}4,30(\mathrm{~A}) \\
(6,10)\end{array}$ & $\begin{array}{c}13,72(\mathrm{~A}) \\
(4,75)\end{array}$ & $\begin{array}{c}6,62(\mathrm{~A}) \\
(3,67)\end{array}$ & $\begin{array}{c}11,13(\mathrm{~A}) \\
(4,67)\end{array}$ & $\begin{array}{c}21,25 \\
(\mathrm{~A}) \\
(4,55)\end{array}$ \\
\hline L-PM & $\begin{array}{c}4,89(\mathrm{~A}) \\
(1,72)\end{array}$ & $\begin{array}{c}16,26(\mathrm{~B}) \\
(6,43)\end{array}$ & $\begin{array}{c}5,01(\mathrm{~B}) \\
(1,21)\end{array}$ & $\begin{array}{c}10,96(\mathrm{~A}) \\
(9,64)\end{array}$ & $\begin{array}{c}23,73 \\
(\mathrm{~A}) \\
(5,08)\end{array}$ \\
\hline H-PM & $\begin{array}{c}4,10(\mathrm{~A}) \\
(12,83)\end{array}$ & $\begin{array}{c}11,33(\mathrm{C}) \\
(2,87)\end{array}$ & $\begin{array}{c}4,94(B) \\
(3,03)\end{array}$ & $\begin{array}{c}9,24(\mathrm{~B}) \\
(6,02)\end{array}$ & $\begin{array}{c}16,83 \\
\text { (B) } \\
(2,95)\end{array}$ \\
\hline
\end{tabular}

Groups with same letters in column indicate that there is no statistical difference $(p<0,05)$ between the samples according to the Duncan's multiple range test.

Coefficient of variation values (\%) are in parentheses. 


\section{Equilibrium moisture content}

Table 4 shows average moisture content values of the OSC panels made from extracted or unextracted wood strands for PF or pMDI resin. The findings of this study show that MC values following conditioning to a relative humidity of $65 \%$ and temperature of $20^{\circ} \mathrm{C}$ of PF or pMDI bonded panels made from extracted wood strands were significantly lower than those of panels made from unextracted wood strands. It could be stated that polysaccharides removed from wood during HWE were predominantly amorphous. These results parallel the findings from Rowell and Banks (1985).

The MC values after $2 \mathrm{~h}$ water soaking period of the panels bonded with PF or pMDI decreased with increasing HWE process severity factors (SF). The MC value after the $2 \mathrm{~h}$ water soaking period of $\mathrm{PF}$ bonded panels from extracted strands with HSF decreased by $33 \%$. The MC value after $24 \mathrm{~h}$ water immersion of PF bonded panels from extracted panels was lower than that of the unextracted panels. The pMDI bonded panels from extracted strands with HSF had the lowest MC values after 24h water immersion. A decrease of 30 and $20 \%$ was observed in the MC values after $24 \mathrm{~h}$ water soaking period of the panels from extracted strands with HSF for PF and pMDI resin, respectively.

The results of this study also indicated that a comparison of the panels bonded with PF or pMDI was not possible due to their physical and chemical properties. However, dimensional stability properties were improved for both resin types.

The results acquired in this study agree with previous studies. Paredes et al. (2008) evaluated TS, WA, and MC of oriented strandboard from HWE red maple. It was stated that the panels from extracted wood had significantly lower EMC values after conditioning than the panels from unextracted wood, but a significant difference between the EMC values after $2 \mathrm{~h}$ or $24 \mathrm{~h}$ water soaking of the panels from extracted wood and the panels from unextracted wood has not been determined. EMC properties of hot water extracted OSB flakes were studied by Sattler et al. (2008). It was reported that HWE flakes had lower EMC values than those of untreated flakes.

When heat has been applied to wood materials, production of acetic and formic acid from hemicelluloses contributes to a cellular breakdown production of condensable fractions, with loss of a high percentage of hemicelluloses, low percentage of lignin, bond water and volatile extractives. Hemicellulose extraction decreases water sorption capacity of wood materials. A decrease in water sorption capacity could result in significant enhancement in dimensional stability characteristics of wood materials when compared to untreated wood materials. The decline on the water absorption values of the panels from extracted strands could be due to less swelling, lower EMC starting, less amorphous polymer, and higher percentage of crystallinity (Hill 2006, Borrega and Karenlampi 2008, Paredes et al. 2009). 


\section{CONCLUSIONS}

The parameters of the hot water extraction process or severity factor affected the weight loss values of the aspen wood strands. When the severity factor increased from 3,56 to 3,84 the increase on the weight loss values of the aspen wood strands was calculated as $27,20 \%$. It could be concluded that the weight loss of the strands was proportional to extraction time. Dimensional stability performance is of great importance to OSC panels used in outdoor applications. Thickness swell, water absorption, and moisture content as characteristics of dimensional stability of the OSC panels made using PF or pMDI resin were significantly affected by the hot water extraction process. The findings obtained in this study indicated that thickness swell and water absorption values after $2 \mathrm{~h}-24 \mathrm{~h}$ - water soaking time significantly decreased with hot water extraction process. One inch inside TS after $2 \mathrm{~h}$ and $24 \mathrm{~h}$ water immersion of the panels with PF decreased with increasing HWE levels and were improved by $70 \%$ and $57 \%$, respectively. The MC values following conditioning to a relative humidity of $65 \%$ and temperature of $20^{\circ} \mathrm{C}$ of PF or pMDI bonded panels from HWE aspen strands were significantly lower than that of the panels from unextracted strands. The panels made using pMDI resin had lower thickness swell and water absorption values than the panels made using PF resin. Equilibrium moisture content values of the panels bonded with both PF and pMDI resin decreased with the HWE process.

The results obtained from this study indicate that the hot water extraction process could be effectively used to produce oriented strand composite panels having enhanced dimensional stability properties which could alter performance of current wood composite panel products in a wide range of applications especially structural building applications. After all, wood composite manufacturers might also have potential advantages for bio-ethanol production by using the aspect of biorefinery.

\section{ACKNOWLEDGEMENTS}

The authors would like to thank Jon Hill, Benjamin Walz, and Jeff for their valuable help during production of the OSC panels and testing procedure, Dwane Hutto, Department of Chemical and Biological Engineering in University of Maine, for his help in hot water extraction procedure. The authors would also like to express thanks to jovial personnel of AEWC Advanced Structures \& Composites Center in The University of Maine for their valuable assistance.

\section{REFERENCES}

Agnihotri, S.; Johnsen, I.A.; Boe, M.S.; Oyaas, K.; Moe, S. 2015. Ethanol organosolv pretreatment of softwood (Picea abies) and sugarcane bagasse for biofuel and biorefinery applications. Wood Sci Technol 49: 881-896.

American Society for Testing and Materials. ASTM. 2006. Standard methods of evaluating the properties of wood-based fiber and particle panel materials. ASTM D 1037-06. Philadelphia, PA, USA.

Ayrilmis, N.; Candan, Z.; White, R.H. 2007. Physical, mechanical, and fire properties of oriented strandboard with fire retardant treated veneers. Holz Roh-Werkst 65(6): 449-558.

BIS Shrapnel. 2008. Oriented strand board (OSB) and lumber (OSL) in the Pacific Rim and Europe: 2008-2012. BIS Shrapnel Pty Ltd, Level 8, 181 Miller Street, North Sydney NSW 2060 Australia. 
Borrega, M.; Karenlampi, P. 2008. Effect of relative humidity on thermal degradation of Norway spruce (Picea abies) wood. J Wood Sci 54(4): 323-328.

Brochmann, J.; Edwardson, C.; Shmulsky, R. 2004. Influence of resin type and flake thickness on properties of OSB. Forest Prod J 54(3): 51-55.

Candan, Z.; Ayrilmis, N.; Akbulut, T. 2011. Dimensional stability performance of fire retardant treated veneer-oriented strandboard composites. BioResources 6(1): 308-316.

Dasmohapatra, S.; Smith, P.M. 2008. Customer value in the oriented strandboard industry. Wood Fiber Sci 40(1): 42-54.

Del Menezzi, C.H.S.; Tomaselli, I. 2006. Contact thermal post-treatment of oriented strandboard to improve dimensional stability: a preliminary study. Holz Roh-Werkst 64(3): 212-217.

Del Menezzi, C.H.S.; Tomaselli, I.; Okino, E.Y.A.; Teixeira, D.E.; Santana, M.A.E. 2009. Thermal modification of consolidated oriented strandboards: effects on dimensional stability, mechanical properties, chemical composition, and surface color. Eur J Wood Wood Prod 67(4): 383396.

Dziurka, D.; Mirski, R.; Dukarska, D.; Derkowski, A. 2015. Possibility of using the expanded polystyrene and rape straw to the manufacture of lightweight particleboards. Maderas-Cienc Tecnol 17(3): 647-656.

Han, G.P.; Wu, Q.L.; Lu, J.Z. 2007. The influence of fines content and panel density on properties of mixed hardwood oriented strandboard. Wood Fiber Sci 39(1): 2-15.

Hill, C.A.S. 2006. Wood Modification: chemical, thermal and other processes. John Wiley \& Sons, Ltd, Chichester, UK, ISBN: 978-0-470-02172-9. 260 p.

Lasure, L.; Zhang, M. 2004. Bioconversion and biorefineries of the future. Draft report from the Pacific Northwest National Laboratory and National Renewable Energy Laboratory, USA.

Lenic, J. 1973. Prehydrolysis of beechwood and its influence on chemical and physical properties of fibres. Paperi Ja Puи 55(4): 325-340.

Liu, S.; Zhang, Z.; Scott, G.M. 2010. The biorefinery: Sustainably renewable route to commodity chemicals, energy, and materials: Selected papers from the Second International Biorefinery Conference (IBC 2009) Syracuse, New York- October 6-9, 2009. Biotechnology Advances 28: 541-542.

Mendes, R.F.; Junior, G.B.; de Almeida, N.F.; Surdi, P.G.; Barbeiro, I.N. 2013a. Effect of thermal treatment on properties of OSB panels. Wood Sci Technol 47: 243-256.

Mendes, R.F.; Junior, G.B.; de Almeida, N.F.; Surdi, P.G.; Barbeiro, I.N. 2013b. Effects of thermal pre-treatment and variables of production on properties of OSB panels of Pinus taeda. Maderas-Cienc Tecnol 15(2): 141-152.

Mosier, N.; Ladisch, C.; Ladisch, M. 2002. Characterization of acid catalytic domains for cellulose hydrolysis and glucose degradation. Biotechnol. Bioeng. 79(6): 610-618.

Mosier, N.; Wyman, C.; Dale, B.; Elander, R.; Lee, Y.Y.; Holtzapple, M.; Ladisch, M. 2005. Features of promising technologies for pretreatment of lignocellulosic biomass. Bioresource Technology 96(6): 673-686.

Okino, E.Y.A.; Teixeira, D.E.; Del Menezzi, C.H.S. 2007. Post-thermal treatment of oriented strandboard (OSB) made from cypress (Cupressus glauca Lam.). Maderas-Cienc Tecnol 9(3): 199-210.

Overend, R.P.; Chornet, E. 1987. Fractionation of lignocellulosics by steam aqueous pretreatments. Philos Trans R Soc A 321(1561): 523-536. 
Paredes, J.J.; Jara, R.; Shaler, S.M.; van Heiningen, A. 2008. Influence of hot water extraction on the physical and mechanical behavior of OSB. Forest Prod J 58(12): 56-62.

Paredes, J.J.; Mills, R.; Shaler, M.S.; Gardner, D.J.; van Heiningen, A. 2009. Surface characterization of red maple strands after hot water extraction. Wood Fiber Sci 41(1): 38-50.

Paszner, L. 2006. Bioethanol: fuel of the future. Pulp \& Paper Canada, April 2006, Canada.

Pelaez-Samaniego, M.R.; Yadama, V.; Lowell, E.; Espinoza-Herrera, R. 2013. A review of wood thermal pretreatments to improve wood composite properties. Wood Sci Technol 47: 1285-1319.

Pelaez-Samaniego, M.R.; Yadama, V.; Garcia-Perez, T.; Lowell, E.; Amidon, T. 2014. Effect of hot water extracted hardwood and softwood chips on particleboard properties. Holzforschung 68(7): 807-815.

Rowell, R.; Banks, W. 1985. Water repellency and dimensional stability of wood. Forest Products Laboratory GTR FPL-50, p 24, Madison, WI, USA.

Sattler, C.; Labbe, N.; Harper, D.; Elder, T.; Rials, T. 2008. Effects of hot water extraction on physical and chemical characteristics of oriented strand board (OSB) wood flakes. Clean 36(8): 674681.

Sekino, N.; Inoue, M.; Irle, M.; Adcock, T. 2005. The mechanisms behind the improved dimensional stability of particleboards made from steam-pretreated particles. Holzforschung 53(4): 435-440.

Shimizu, K. 1990. Chemistry of hemicellulose. Wood and Cellulosic Chemistry 5: 177-214.

Sumardi, I.; Ono, K.; Suzuki, S. 2007. Effect of board density and layer structure on the mechanical properties of bamboo oriented strandboard. J Wood Sci 53(6): 510-515.

Tan, T.; Xu, J.H. 2010. Biorefinery: an efficient way to sustainable development of chemical industry-a special issue for international conference on biorefinery (ICB 07) and the $5^{\text {th }}$ international conference on separation science and technology (ICSST2007). Appl Biochem Biotechnol 160: 301302.

Unsal, O.; Candan, Z.; Buyuksari, U. 2009. Thickness swelling and wettability of structural wood based panels affected by heat treatment. COST E49 Action, Processes and Performance of Wood Based Panels, April 28-29, 2009, Istanbul, TURKEY.

Unsal, O.; Candan, Z.; Buyuksari, U.; Korkut, S.; Babiak, M. 2010. Effects of thermal modification on surface characteristics of OSB panels. Wood Research 55(4): 51-58.

van Heiningen, A.R.P. 2006. Converting a kraft pulp mill into an integrated forest biorefinery. Pulp Paper Canada 107(6): 38-43.

TECO. 2009. OSB Guide, OSB Fast Facts. Terra Court, Sun Prairie, WI, USA.

Tunc, M.S.; van Heiningen, A.R.P. 2008. Hemicellulose extraction of mixed southern hardwood with water at $150^{\circ} \mathrm{C}$ : effect of time. Ind Eng Chem Res 47(18): 7031-7037.

Wan, H.; Kim, M. 2006. Southern pine wood and strands impregnated with low levels of butanetetracarboxylic acid as stabilizing agent for oriented strandboard. Wood Fiber Sci. 38(1): 144154.

Wu, Q.; Suchsland, O. 1996. Linear expansion and its relationship to moisture content change for commercial oriented strand boards. Forest Prod J 46(11/12): 79-83. 
Zisi, N.V., Bennett, R.M.; Van Houts, J.H. 2005. Dimensional stability and mechanical properties of oriented strandboard with microwave-dried flakes in the surface layers. Forest Prod J 55(12): 136142. 